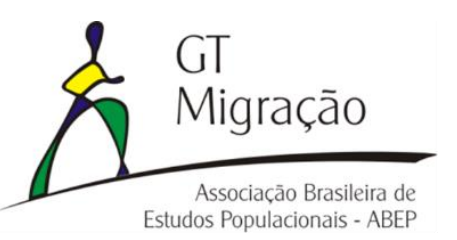

\section{O efeito da migração sobre o crescimento populacional da cidade de Parnamirim- \\ RN, 2000 a 2012}

\author{
Rosimere Lopes Monte \\ Luana Junqueira Dias Myrrha *
}

\title{
Introdução
}

A Região Metropolitana de Natal vem vivenciando uma acelerada ocupação de habitantes, atraídos ou motivados pela demanda de mão de obra, gerada pelas políticas públicas e privadas de empreendimentos na capital (NICOLAU, 2008). Consequentemente, o número elevado de imigrantes provocou um rápido processo de ocupação e um significativo crescimento populacional na região, o que demandou a construção de novas moradias e a comercialização de imóveis (SOUZA, 2004). Com esse grande fluxo migratório ocorreu um dinamismo econômico em várias atividades, em especial na cidade de Parnamirim, que pertence a região metropolitana de Natal e faz fronteira com capital (SOUZA, 2004).

De acordo com as informações dos Censos Demográficos 2000 e 2010, o município de Parnamirim teve um crescimento de 62,4\% nesse período de 10 anos, passando de 124.690 habitantes para 202.456 habitantes. Além de Natal (R \$11.997.401), Mossoró (R \$3.496.776) e Guamaré (R \$1.197.834), Parnamirim está dentro do grupo de municípios que exerce maior representatividade para contribuição no PIB do estado do $\mathrm{RN}$ - R\$2.350.562 (2010), equivalente a 7,3\% em relação ao PIB total estadual (2010) (CLEMENTINO \& FERREIRA, 2015). O setor que mais cresceu foi o terciário, na ampliação de novos serviços administrativos, ramos de atividades, educação, comércio em geral, saúde e lazer. Com esse desenvolvimento urbano, a cidade ganhou mais atividades turísticas, pois além de ser uma cidade histórica que teve participação conjunta com esforços de guerra na Base Aérea de Natal ela ocupa uma área litorânea tornando um atrativo aos visitantes (GIESTA, 2013).

Este trabalho busca avaliar a dinâmica demográfica da cidade de Parnamirim em seus aspectos mais gerais, estimando o efeito da migração e dos eventos vitais

\footnotetext{
- Mestranda em Demografia pelo Programa de Pós-graduação em Demografia da Universidade Federal do Rio Grande do Norte - UFRN
} 


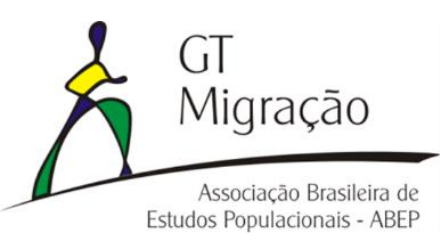

X Encontro Nacional sobre Migração

UFRN - Universidade Federal do Rio Grande do Norte

Natal, Brasil 16 a 18 de outubro de 2017

(nascimentos e óbitos) sobre as taxas de crescimento anuais dessa população. Espera-se que os resultados possam servir de base para a elaboração de políticas públicas com embasamento científico, de forma a melhorar a qualidade de vida da população.

\section{Material e Métodos}

Os dados sobre população, óbitos e nascimentos de Parnamirim/RN, para o período de 2000 a 2012 foram extraídos do Departamento de Informática do SUS DATASUS. Para a análise da dinâmica demográfica, utilizou-se a decomposição da Taxa Bruta de Crescimento populacional (TBC), que corresponde à soma da Taxa Bruta do Crescimento Natural (TBCN) e a Taxa Bruta da Migração Liquida (TBML) (PRESTON ET AL, 2002). A TBCN representa o quanto a população cresceu em função dos seus eventos vitais (nascimentos menos óbitos), ou seja, corresponde à diferença entre as taxas brutas de natalidade e mortalidade. $\mathrm{O}$ efeito da migração sobre o crescimento populacional é representado pela TBML, que corresponde à diferença entra a Taxa Bruta de Imigração e a Taxa Bruta de Emigração. Portanto, pela decomposição da TBC será possível estimar qual é a participação da migração no crescimento da cidade de Parnamirim, frente ao peso dos eventos vitais. As analises serão realizadas para cada ano do período em estudo, para os quais se tem a contagem dos nascimentos e óbitos. As informações sobre o tamanho da população foram estimadas pelo IBGE e as informações da migração será estimada pelo resíduo, ou seja, pela diferença entre a TBC e a TBCN, uma vez que não se tem a informação da migração de estoque ano a ano pelo Censo Demográfico.

\section{Resultados e Discussão}

Os resultados evidenciam que no período intercensitário (2000-2010) a população da cidade de Parnamirim cresceu 62,4\%. O seu incremento populacional de 2000 para 2010 foi de 77.766 habitantes, dos quais apenas 27.691 habitantes foram consequência dos eventos vitais (nascimentos menos óbitos). Portanto, pode-se inferir que o restante, que corresponde a $64,4 \%$ do incremento populacional, representa o efeito da migração.

No entanto, há limitações nos resultados da estimação da participação da migração, pois a população ano a ano não é recenseada e sim estimada por taxas de crescimento intercensitária. Consequentemente, as estimativas da migração que foram calculadas por resíduo poder carregar erros de estimação da população. Além disso, existem subregistros 


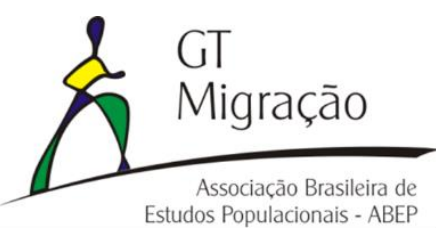

\section{Encontro Nacional sobre Migração \\ UFRN - Universidade Federal do Rio Grande do Norte Natal, Brasil 16 a 18 de outubro de 2017}

dos eventos vitais, isso também pode interferir na estimação da migração. Diante disso, o resultado mostrado para os anos de 2007 a 2009 pode estar sujeito a esses fatores. Em que, nos demais anos o efeito da migração se sobrepôs ao efeito do crescimento natural (Gráfico 1).

Gráfico 1: Participação da Taxa Bruta do Crescimento Natural (TBCN) e da Taxa Bruta da Migração Liquida (TBML) na Taxa Bruta de Crescimento populacional (TBC) da cidade de Parnamirim-RN, 2000 a 2012.

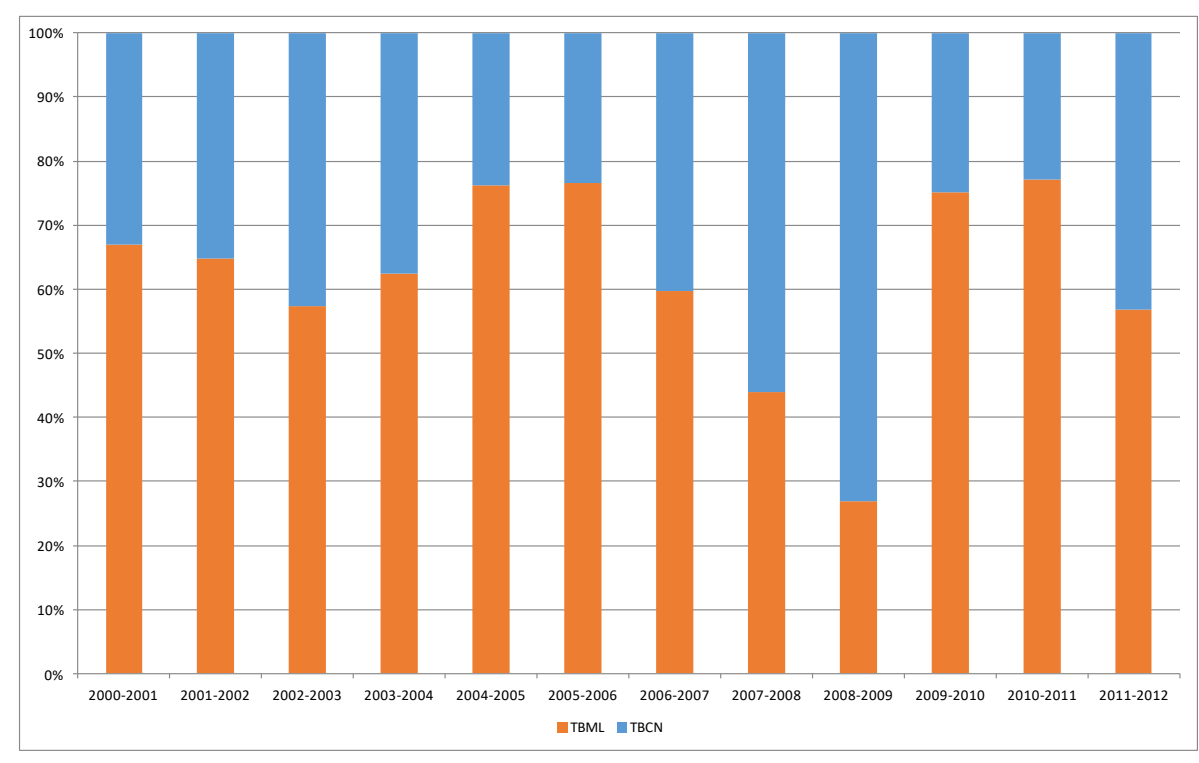

Fonte dos dados básicos: DATASUS, 2000 a 2012

A metodologia adotada não permite separar o efeito indireto da migração dos nascimentos totais, por isso, espera-se que o efeito da migração seja ainda maior, na medida em que os filhos dos migrantes nascidos em Parnamirim não estão sendo contabilizados no efeito da migração.

Os resultados sugerem que grande parte do crescimento da cidade de Parnamirim é consequência da absorção de imigrantes que vieram para região metropolitana de Natal advindos de outras localidades, bem como de imigrantes da própria região metropolitana. Os imigrantes têm como principais atrativos a proximidade de Parnamirim da capital, o que permite os movimentos pendulares, a expansão imobiliária e o desenvolvimento de novos serviços administrativos, da educação, do comércio, da saúde e do lazer.

Os migrantes tendem a ter um perfil etário jovem ou adulto, pois as motivações de migrar geralmente estão relacionadas com as oportunidades de trabalho e estudo. 


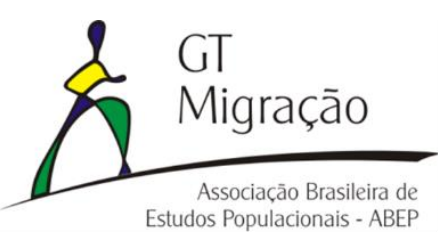

\section{Encontro Nacional sobre Migração \\ UFRN - Universidade Federal do Rio Grande do Norte Natal, Brasil 16 a 18 de outubro de 2017}

Nesse sentido, é importante que a cidade esteja preparada para atender as demandas desse perfil, que se concentram em habitação, educação e comércio. Além disso, um planejamento urbano e regional deve ser tomado como prioridade, com o objetivo de integrar as atividades cotidianas dos indivíduos e facilitar os fluxos de deslocamentos pendulares.

\section{Conclusão}

Os resultados evidenciam que o efeito da migração se sobrepôs ao efeito dos eventos vitais no crescimento da cidade de Parnamirim, ao longo dos anos de 2000 a 2012. A cidade, por pertencer a região metropolitana de Natal, fazer fronteira com a capital e vivenciar um desenvolvimento em diversas áreas, tem atraído a população que chega à região metropolitana e a população da própria região metropolitana. Portanto, a cidade de Parnamirim pode ser considerada como um destino natural do crescimento urbano da capital do RN, Natal.

\section{Referências}

GIESTA, J. P. Outorga onerosa do direito de construir e dinâmica do mercado imobiliário formal: planejamento e descaminhos na expansão urbana de Parnamirim RN (2008-2010). Dissertação, Universidade Federal do Rio Grande do Norte, Natal, 2013.

CLEMENTINO, M. L. M.; FERREIRA, A. L. Natal: transformação na ordem urbana. Natal: Letrcapital, 2015, p. 53-56.

Instituto Brasileiro de Geografia e Estatística/Sistema IBGE de Recuperação Automática - IBGE/SIDRA Disponível em:

http://www.sidra.ibge.gov.br/bda/acervo/acervo2.asp? $=\mathrm{e} \& \mathrm{p}=\mathrm{CD} \& \mathrm{z}=\mathrm{t} \& \mathrm{o}=25$.

Acessado em: 20 mar 2016.

NICOLAU, D. G. B. A produção capitalista do espaço: os loteamentos, os condomínios fechados e o seu papel na formação do bairro de Nova Parnamirim/Parnamirim-RN. Dissertação, Universidade Federal do Rio Grande do Norte, Natal, 2008.

PRESTON, S. H., HEUVELINE, P., GUILLOT, M. Demography: Meansuring and Modeling Population Processes, 1ed. Blackwell Publishing Ltd, 2001, p. 291

SOUZA, F. E. O processo de reprodução de Espaço Urbano de Nova Parnamirim. Dissertação, Universidade Federal do Rio Grande do Norte, Natal, 2004. 